1719. Malik. Transformative

https://doi.org/10.30953/tmt.v2.29

Page 1 of 15

\title{
Transformative Health Management Utilizing Real-time Data from the Home in a Meaningful Way
}

Samir Malik

Editor's note: On March 16th and 17th, 2017, Telehealth and Medicine Today convened a national conference of opinion leaders to discuss and debate "Technologies and Tactics Transforming Long-term Care." What follows is a lecture by Samir Malik on the topic of mental healthcare, and home health.

I was asked to come here and speak about our experience building telehealth programs that have grown in a sustainable way, focusing on reimbursement, but also patient care.

\section{Background [00:18]}

So, a little bit of background about our organization. We've been focused on increasing access to mental healthcare for under-served populations for about six years-targeting Medicaid patients and Medicare patients, primarily. Over those six years we've grown to become the largest outpatient telepsychiatry provider in the country-serving over 50,000 patients across the United States. The story I'll share is a little bit about how we got there.

We're located in New York City. We primarily focus our care throughout the country.

About a year-and-a-half ago we were acquired by a much larger healthcare organization called Genoa, which focuses on building onsite pharmacies inside community mental health settings - the goal being to complement our telemedicine services with onsite pharmacy and start coordinating care in a more meaningful way. We still operate independently as our own operations in New York. Genoa, in Seattle, focuses on the pharmacy business (Fig. 1). 
1719. Malik. Transformative https://doi.org/10.30953/tmt.v2.29

Page 2 of 15

\section{Genoa Telepsychiatry}

- A nationwide telepsychiatry provider with a footprint in $15+$ states

- Largest outpatient programs in the country, treated $>30,000$ patients during 5-year history

- Founded in 2011; located in New York City

- Programs administered in inpatient units, emergency departments, community mental health centers, and primary care settings

- Services delivered using HIPAA-compliant video conferencing software, which includes appointment scheduler, notes, and prescription tools

- Part of Genoa, a QoL Company

- Largest nationwide retail pharmacy firm, with significant penetration in community mental health centers

- Founded in 2000 , headquartered in Seattle, Washington

- 300+ locations in 40 states

- Serves approximately 360,000 patients annually

- Opened an average 34 de novo pharmacies annually over past 3 years, including 40 in 2015

Figure 1. Genoa telepsychiatry

\section{Myths about Telehealth [01:13]}

I was asked to talk about dispelling some myths. Often, we hear that reimbursement is unproven in telehealth, and that's a barrier to entry; or that technology is expensive. The folks from Vizio Medical Devices showed us that technology isn't necessarily all that expensive. I see VSee sitting out front, another great platform you can use to deliver technology in a much more affordable way than perhaps existed five or ten years ago.

We're at a place now in the telehealth ecosystem where (and I think the very first presenter I got to see was speaking about this) technology on its own is not going to be the driving force to a telehealth program's success. Success is about building the operations in the workflows and the systems around it to make it work.

And the last piece that we often hear around myths is that telemedicine isn't as effective as in-person consultations. In our space, in behavioral health, that is certainly dispelled. Academia has discussed this and considered it for six or seven years now. And on a double-blind basis, you can find that outcomes and diagnostic accuracy end up being just as good for in-person consultations as they are for telemedicine consultations. 
1719. Malik. Transformative https://doi.org/10.30953/tmt.v2.29

Page 3 of 15

We're now a team of about 180 psychiatrists working for us, and I can tell you out of our experience that what matters far more than the technology medium by which a patient is seeing a doctor is the quality of the doctor on the other side. A great doctor makes telemedicine disappear. The technology goes away, and the doctor and patient are able to connect and have a very meaningful relationship. Technology won't save a "bad' doctor. A "bad" doctor is a "bad" doctor whether he has all the greatest telemedicine tools in the world or not. And so, what we're finding is that telemedicine is now largely a function of the quality of the care that's being delivered, less a function of the perception of whether the care is effective or not effective over the medium.

\section{Facts about Telehealth [03:21]}

With those minutes touched on we'll continue to discuss them. I want to share facts you can build programs that grow. You can build programs that have "stickiness" where patients come back again and again and again for consultation if you have the right things under consideration.

So, just sharing our real data (Fig. 2). This is how many visits we've conducted over the years, climbing now up to 50,000 visits, and you can see acceleration as every week we see more and more visits being created. So, the hockey stick only gets steeper. I show this not to say we're great. I show this to say that if you get the underlying factors right anybody can go out and achieve this type of growth in their telemedicine programs. 


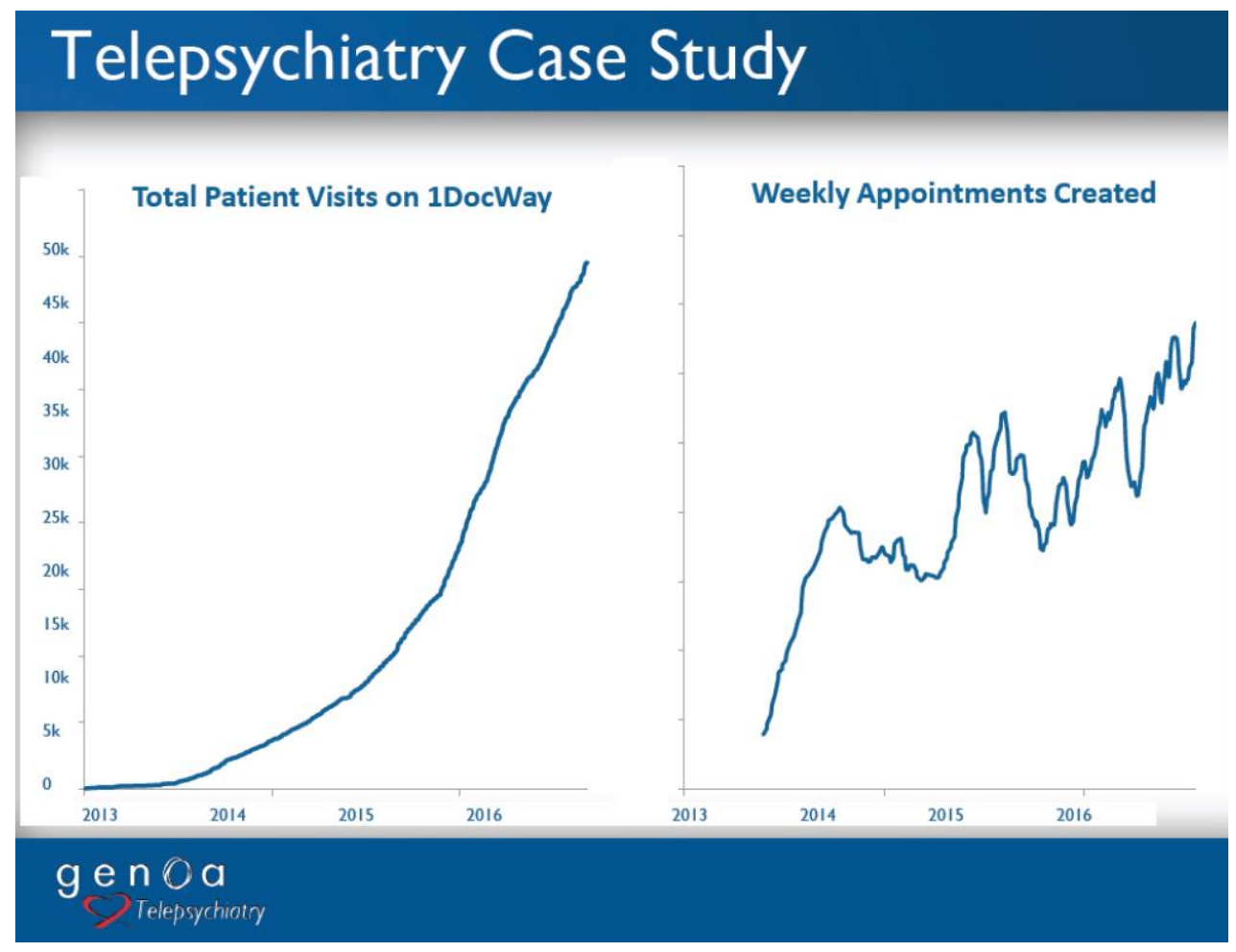

Figure 1. Growth inpatient visits and weekly appointments created since 2013.

\section{Considerations for a Telemedicine Model [04:07]}

So, a little bit about what the model must look in our experience. First, is working with the facilities that have built the infrastructure to serve the patients you're targeting. We don't need to reinvent the wheel. We're often out there working with community mental health clinics or clinics on military bases; and setting up telepsychiatry in those care settings, because those are the facilities that have done the hard work of engaging these communities.

If you're a patient in Meridian, Alabama or a naval base in Osawatomie, Kansas, you are not going to think about consuming care in a new way. You're going to go to your old habit. There's a clinic down the street or a clinic around the corner. That infrastructure is there. So, we tap into that infrastructure. Our psychiatrists are treating patients when they present at any of these clinics across the country. We're not trying to start up a new system, but rather, adapt our providers to the systems that exist. 
1719. Malik. Transformative

https://doi.org/10.30953/tmt.v2.29

Page 5 of 15

So, when our providers are partnering with these facilities: skilled nursing: community hospitals, FQHC (Federal Qualified Health Center), you name it, our providers are really becoming part of that clinics care team. If there are certain documentation standards, if there are certain treatment team planning meetings, if there are certain care philosophies that need to be applied in these care settings, our doctors are required to adapt and treat using those principles. That helps us be part of the existing infrastructure, rather than trying to redirect patients who are already underserved into another decision that they may not want to make.

And so, as we think about what this means, well, certainly as an organization we're able to grow; but you only do that when you have buy-in from all your stakeholders. So, our stakeholders are certainly those spokes sites receiving care, and we're able to put these programs together in a way that's monetized for them. We'll talk about reimbursement in a moment, but across our 80 some sites in the country, they're on average making money on their telemedicine programs; and keep in mind we're serving 95\% Medicaid. If you can make money serving Medicaid patients you can make money doing just about anything.

Telemedicine can do this, but you must be smart about how you design the programand we'll get into that. You can't set up a program where patients to try it once and then disappear. Acquisition costs for patient care are too high in our system to just have one touch point, one interaction. I think this was discussed in that Health Spot article that just won an award, which is you've got to find a way to manage chronic disease and do so in effective manner. If you do, patients come back, and your customer acquisition cost gets amortized well over the life of treating that disease. So, think about attracting the populations in a way that encourages repeat visits. The single visits are hard to make the economics work.

And lastly on the physicians, if you don't have buy-in from physicians you will lack the supply in the marketplace. For our business in psychiatry, this is particularly pertinent 
1719. Malik. Transformative

https://doi.org/10.30953/tmt.v2.29

Page 6 of 15

because psychiatry is so underserved. But if you're looking at primary care, if you're looking at dermatology, some other spaces, that may not be as big of an issue. But even still, being able to manage your physician stakeholder or provider stakeholder in a meaningful way is going to be foundational.

Our business today is bottlenecked because we don't have enough providers. We have 180 psychiatrists working with us. That's not nearly enough to meet the need that's out there. But we're able to attract them because we're shifting them away from a model, which was subjecting them to fee-for-service risk or low Medicaid reimbursement rate. We're paying our doctors by the hour and whether a patient no shows or whether a patient is cash pay or self-pay, or whatever the case may be, our doctors make the same amount of money. We're the ones taking the risk. Navigating that risk the right way is important. It allows us to recruit quality providers, getting back to the essence of what's going to build a sustainable program

The market is massive and nobody needs to go into too much detail on this. We all know this, and we're all here because we recognize that patients are under-served in every different care setting that you can imagine. And there are 80 million of them in this country that live in designated under-served areas, before you even think about folks who may be in long-term care settings or skilled nursing settings who simply don't have access to specialists in an easy way.

\section{Making the Model Work [08:35]}

I spoke a little bit about what goes into making the model work. It starts with identifying the facilities on the ground, and really any facility has been in our wheel house over the past six years, whether you're talking about a geriatric population in long-term care, or skilled nursing, or a youth population in social service agencies or foster homes patients. Patients are everywhere, and finding those stakeholders who are already looking out for patients and recognizing that these patients have a need for something specific that you can offer is the foundational driver to a program's success. 
1719. Malik. Transformative https://doi.org/10.30953/tmt.v2.29

Page 7 of 15

We used to try to push programs down clinics throats. We would go to a primary care office and say, "Oh, you don't have behavioral health? Primary care in behavioral health is the future. You should absolutely do this." And we would try to force it upon them, and do an educational sell, and demonstrate why it's important, and demonstrate why they'd make money. But at the end of the day, if that clinic doesn't recognize the need you're not going to get that far with them.

We would get those sales. We have sales people who are good at making the case, but once the rubber hits the road and the providers responsible for sending patients to the program, that lack buy-in is really the gap. So, we've reoriented our strategy, and that's a learning that I think we can share with everyone, which is really search out for demand. It's there, you know, we're are in healthcare. Healthcare is a space which at the most macroeconomic level, demand is outstripping supply.

We're all supply providers in one capacity or another. So, go find the demand. Go find the most acute areas where there are needs. And, if you can serve in that place you're going to run out of the gates with a blast! And, when you do that you see longevity too.

When we would force programs down clinic's throats. They'd try it for six months, and then they'd leave. Maybe we'd make some of our money back, we'd break even on it. But where we do well as a business is when clinics are bought in to us in long-term ways. Our average provider has now been partnered with a given facility for over 24 months, and that number continues to grow because we're adding more and more to our business every day. That's where you can start to get the long-term return.

It's the same principle as the customer acquisition cost. The longer the relationship you have with your partners in this space, the more you're going to benefit, the more the patients are going to benefit, and, to be frank, thinking about the supply constraints in telemedicine markets, the easier it is on your providers. Doctors don't want to be bouncing arounds. They don't like bouncing around case by case, clinic by clinic. They want to have meaningful relationships with other clinicians, nurses. They want to be 
1719. Malik. Transformative https://doi.org/10.30953/tmt.v2.29

Page 8 of 15

able to work with patients through the longitudinally of their disease. So, setting programs up like that can set you up for success in a meaningful way.

\section{Profiling the Successful Program [11:21]}

What does it look like when you've considered all your stakeholders and tried to figure out what program is going to work well for all of them? Well, first off, the clinics, what we see is that they like the programs and they continue to buy. This is just a sample for from Illinois. It gives you a sense of the average clinic may start by buying four hours of a psychiatrist time from us, and then over time realize this is working well, and I'm not losing money, and patients need to, and demand outstrips supply. So, let me add more time.

We see $50 \%$ same store growth year-over-year among certain clinics over a two-year period-meaning not only do they try it but then they end up committing more and more time and more and more resources to these programs as you go (Fig. 3). The clinics wouldn't be doing this if they were losing money and they looked at their numbers after six months or a year and saw otherwise.

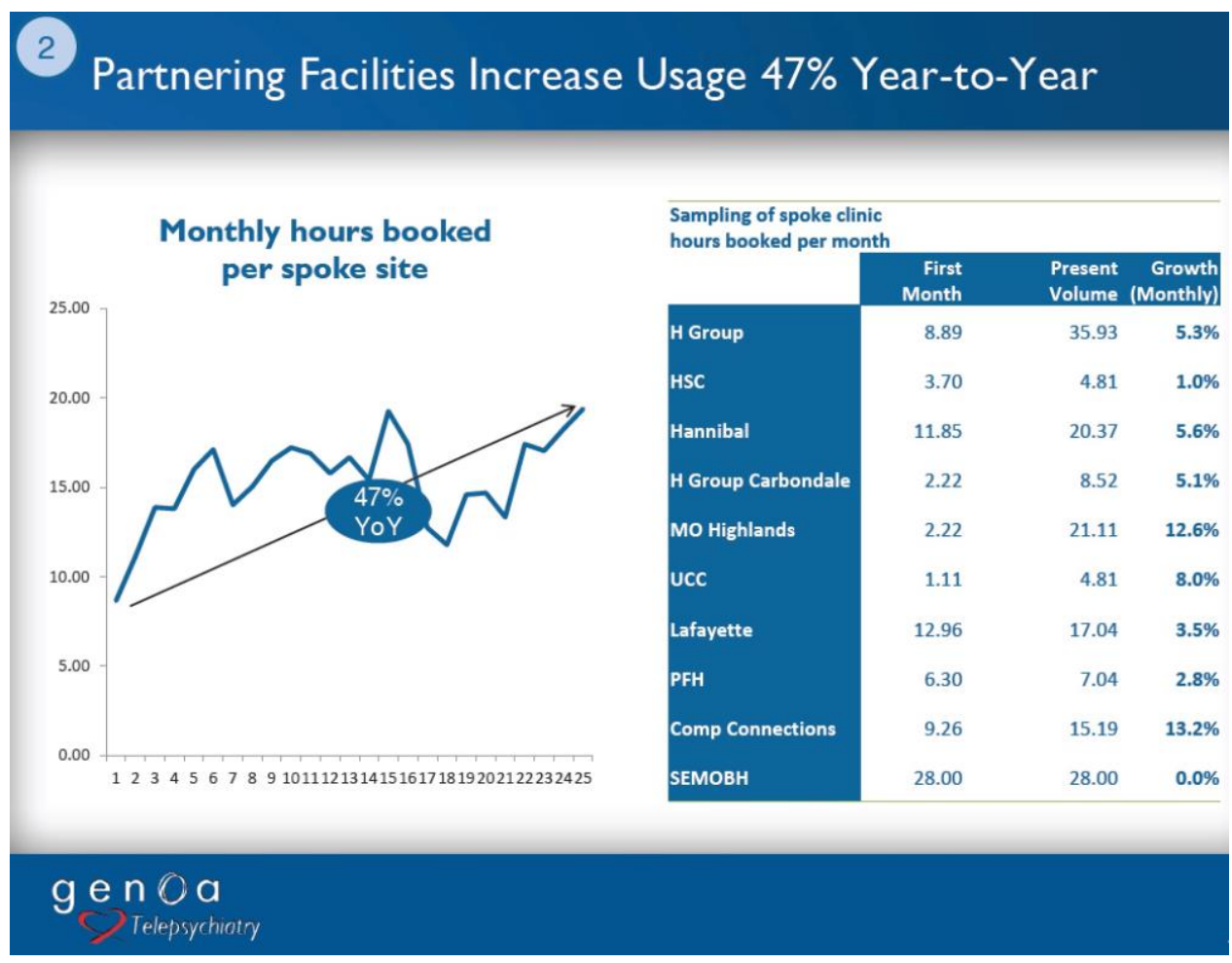


1719. Malik. Transformative https://doi.org/10.30953/tmt.v2.29

Page 9 of 15

Figure 3. Sample of growth in telehealth services.

Same thing with the patients; $85 \%$ of all the visits done over our platform have been follow up visits, meaning patients have done it once, and they realized this is meaningful, and I got the care I was looking for, and I enjoyed the relationship with the provider on the other side, and I want to come back for more (Fig. 4). In fact, our average patient has done over six appointments over a session, again demonstrating that there is both business value and patient value in the longitudinally of patient care.

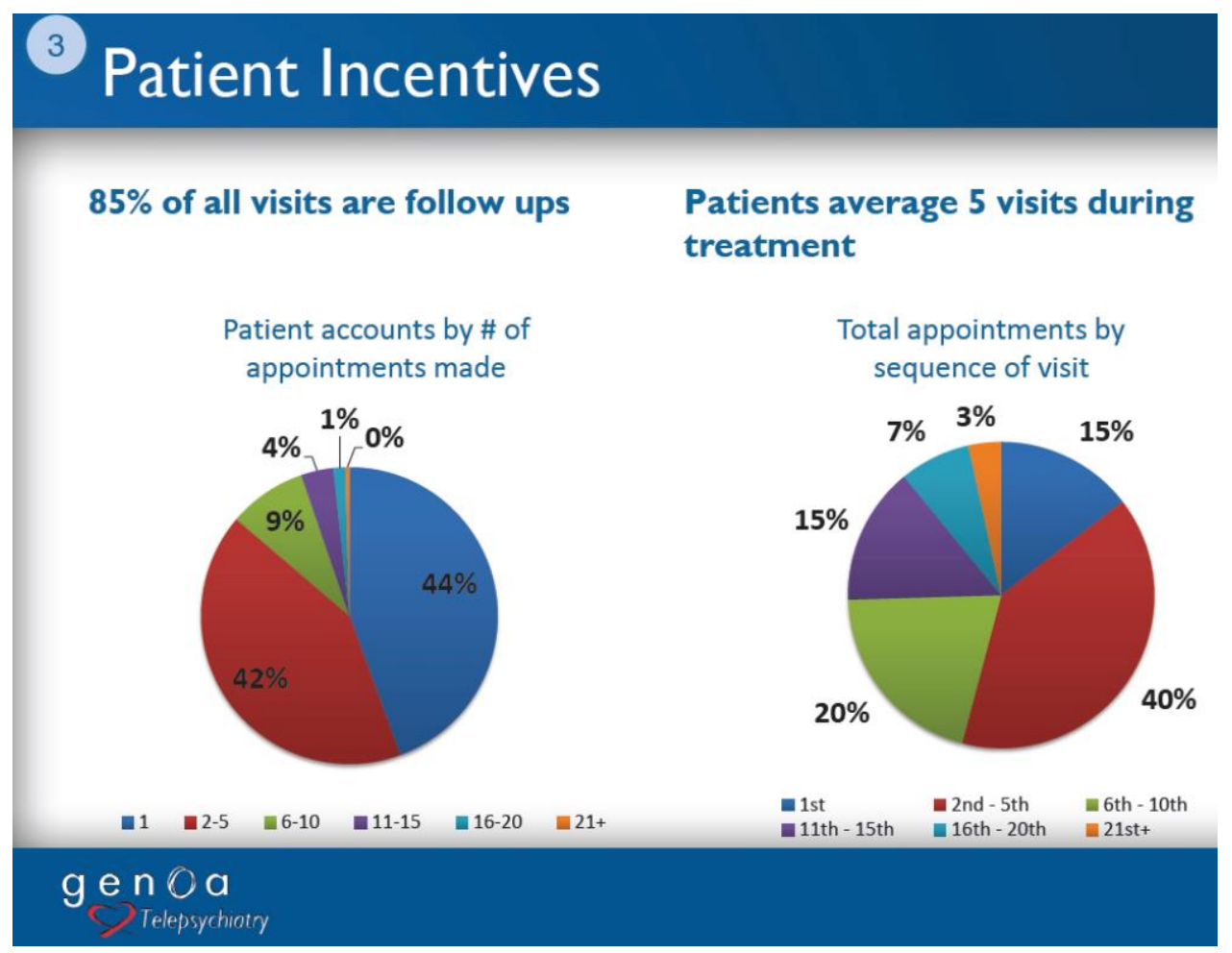

Figure 4. Number of appointments make and sequence of visits.

And, you can see that $25 \%$ of our patients have done more than ten visits. And we've got some patients who have been around for three or four years, now in the 30, 40, 50 visit range. Where basically patients whole entire psychiatric care experience has been done via telemedicine. It's possible if you build the programs the way they cater to the stakeholders. 
1719. Malik. Transformative https://doi.org/10.30953/tmt.v2.29

Page 10 of 15

Lastly, on the physician side of things, I mentioned guaranteed pay upfront. Doctors approach us the same way clinics approach us. "I've heard about telemedicine." "I'm interested in learning more." "I'm going to dip my toe in the water." And they start with maybe two or three hours a week of care that they commit to us. But over time, as they realize that they're enjoying the relationship they're developing with the clinicians on the other side - that they develop very meaningful doctor patient relationships to improve the lives of those in under-served care settings-they end up ramping up with us in a meaningful way (Fig. 5).

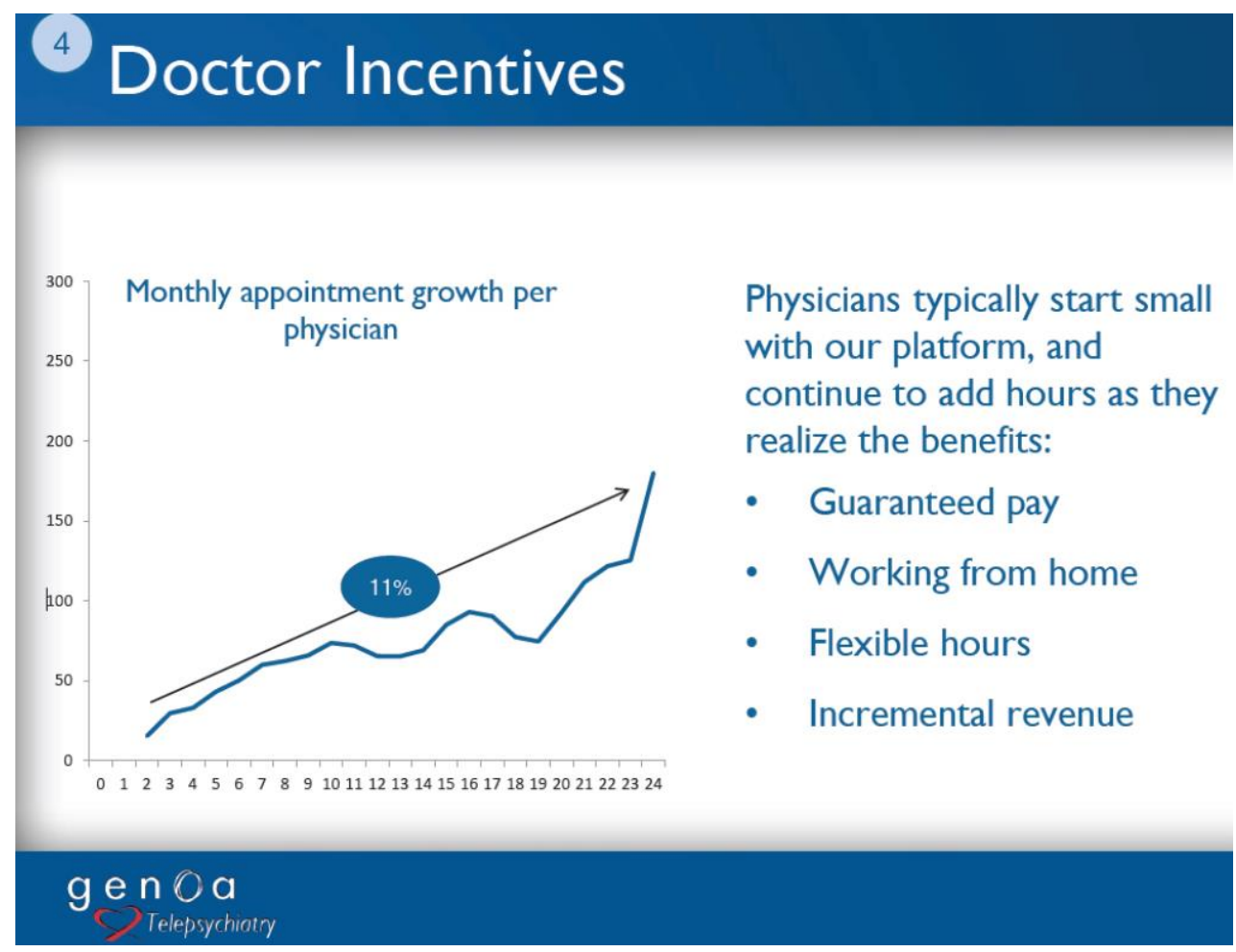

Figure 5. Physician incentives and growth over time.

You'll see this uptick right towards the end of year two. And the reason we see a big bump at that point is that the average doctor we're engaging with is on some sort of commitment with their current employer-a 2-year contract or 4-year contract. And as soon as that expires they're saying I want to give you all my time. So, that's why you see that bump right at the end in terms of doctors really being interested in coming to us more and more. 
1719. Malik. Transformative

https://doi.org/10.30953/tmt.v2.29

Page 11 of 15

The moral of the story is if you build a program that serves your stakeholders by compensating doctors and providing them meaningful work, treating patients in a way that they find satisfactory - and perhaps even better than they would receive resources otherwise-and addressing the financial needs of your clinic partners or hospital partners in these programs, everything is up and to the right.

It's intuitive from a textbook perspective, but implementing programs like this is hard. So, I don't need to go into too much more detail about what we do. I really want to save some time for a conversation. From you all you know, what questions you may have, experiences you might have about setting up telemedicine programs. If you all have tried things like this and it's just not clicking, let's discuss. Let's figure out where we can problem solve and perhaps set things up the right way. Yes, sir.

\section{Discussion}

\section{Q: How do you handle providers across state lines? [14:58]}

Mr. Malik: We've got 180 providers licensed in 48 states. We have an internal licensing and credentialing team that will work on sometimes cross-licensing providers.

For example, child psychiatry in Kansas is a very hard problem for us to solve. So, our team will take our child psychiatrists from Indiana and North Carolina and get them Kansas licenses.

It takes time. It takes three months, four months, five months; but once you've done that, you're expanding supply in the marketplace in a really differentiated way. So, we have an in-house licensing and credentialing team who will do all the paperwork for a doc.

\section{Q: So, on the spoke sites, how do you serve them regarding billing?[15:40]}

Mr. Malik: We'll walk all our spokes sites through what reimbursement for telepsychiatry looks like. We give them guidance on codes. Our providers will document the CPT ${ }^{\circledR}$ 
1719. Malik. Transformative

https://doi.org/10.30953/tmt.v2.29

Page 12 of 15

(Current Procedural Terminology) codes for them to bill. We'll make sure they're capturing the facility fee where possible.

They collect all those funds and then pass back to us a flat hourly rate.

And the reason clinics can make money on this is because of that $Q$ code (miscellaneous services). I think this was discussed earlier, but you know Medicare pays $\$ 25$ a pop for the $Q$ code. So, if a doctor is seeing four patients an hour in follow ups, that's $\$ 100$ additional reimbursement if you can manage utilization well.

The biggest gap between what I just said in actual execution is patient utilization. No show rates kill the financial sustainability of a program.

\section{Q: How do you monitor and ensure quality? [16:33]}

Mr. Malik: Internally, we have a philosophy that good doctors are made not found. We just need to help make them. So, what resources do we have? What tools can we offer a provider to make their life easier?

The truth is we haven't had $100 \%$ success rate-maybe not even $50 \%$. Sometimes we just come across providers whom we have not been successful in helping them provide quality care.

Tools that we have, first off from a diagnostic standpoint, and we do both internal chart reviews by our medical director who will review the documentation from each of our providers, and we also do patient satisfaction surveys at the end of every appointment. When we se e a provider drop below a 4 (kind of like am Uber driver) we'll spend special attention on that physician to see (on a scale of 5 , so below a 4 is concerning) and start working with the provider to understand. Is it bedside manner? Is it communication? Is it the way you present yourself in front of the computer? And to the extent that we can provide remediation we do. But the honest answer is we're not $100 \%$ successful in that effort. 
1719. Malik. Transformative

https://doi.org/10.30953/tmt.v2.29

Page 13 of 15

\section{Q; Is there something different about a computer interface that is sufficiently} different from in-person contact that you can distill it, transport it, monitor it, and train for it to maintain quality? [17:44]

Mr. Malik: There are factors that are unique to telemedicine and those are all straightforward. Those are, you know, always look at the camera not the screen because the camera's picking up your eyes. It's don't have a second monitor open and document over there. Our platform allows you to document and to do the video session in one panel. Give the patient your attention, Don't back-light the room. You'd be surprised how disturbing the negative silhouette can be to a patient in a schizophrenic state.

So, you want to take the low-hanging fruit off the table. So, we do that, but it's not only that that is required to fix the problem sometimes.

\section{Q: Are these wait times a special situation? [18:39]}

Mr. Malik: These wait times are in situations, across the board, where we're adding provider supply to an existing clinic. So, a clinic may have one psychiatrist already, but that psychiatrist is fully booked, and a patient must wait 6 weeks, 8 weeks, 12 weeks to see that provider.

When we go to a primary care site that didn't have any psychiatry before, our baseline number is based on if you went out into the community and found a psychiatrist elsewhere how long would that have taken? So, we'll go to a clinic where there was never any mental health before and provide the services there, but then when we're comparing before and after we're saying how long did you wait when you went to the town next door to get a psychiatrist versus how long do you wait now to see a provider.

\section{Q: How are your doctors compensated? [19:26]}

Mr. Malik: Yes. doctor compensation is not tied to patient satisfaction. There are two independent variables; and doctors are paid by the hour on a pre-negotiated rate. If we 
1719. Malik. Transformative

https://doi.org/10.30953/tmt.v2.29

Page 14 of 15

do see low patient satisfaction we'll have our medical director review and interview patients, and try to understand why. And if there is a clinical competency driving that, then we'll have a discussion with the provider. But we're not moving their compensation based on high performance, low performance.

Yes. last question.

\section{Q: If the patient doesn't show up, who gets penalized? [19:57]}

Mr. Malik: In our remodel the clinic will get penalized. The clinic is on contract with us for a fixed block of time, and so if the patient doesn't show the clinic is paying us for the doctor, without having a patient to generate revenue on the other side.

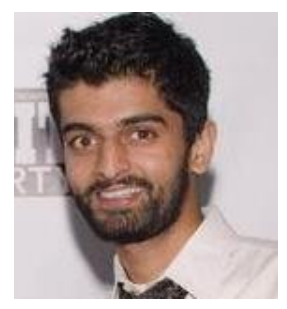

Samir Malik is Senior Vice President and General Manager of Genoa Telepsychiatry, part of Genoa, a QoL Healthcare company. He was previously CEO of a New York Citybased telepsychiatry company. Mr. Malik and his team have the experience of building a successful technology-enabled-services company from scratch, treating 50,000 patients across the country.

Samir earned a Bachelor of Science in Economics degree from the Wharton School at the University of Pennsylvania magna cum laude, a Bachelor of Arts in Neuroscience from the University of Pennsylvania with distinction, and a Master's of Business Administration at Wharton in Healthcare Management.

Tags: Genoa Telepsychiatry, home telehealth, implementing telehealth, mental health, myths about telepsychiatry, physician buy-in, Samir Malik, search for demand 
1719. Malik. Transformative https://doi.org/10.30953/tmt.v2.29

Page 15 of 15 